\title{
Over-Supply and Manufacturing Localization
}

\author{
Maria Emilia Garbelli*
}

\begin{abstract}
Manufacturing localization in over-supply markets is a particularly complex problem. The starting point is the set of principles on which a localization choice is usually based (proximity to the outlet and supply markets, state-related incentives, etc.). However, such a choice cannot be made without taking several additional factors into account - from the unsold goods problem to the cooperation between companies.

In contexts characterized by instability, market-driven businesses pursue a double advantage: they assign a central role to market requirements while showing open mindedness and a readiness to react to the many rapid changes in the context.

Market instability is reflected in the manufacturing sites, by quickly cancelling out benefits derived from the adopted localization solutions, and thus making it difficult for businesses to make choices, that is, adopting options that remain valid and almost unchanged over the long term.
\end{abstract}

Keywords: Over-Supply; Manufacturing Localization; Manufacturing Localization Choices; Dynamic Localization; Market-Driven Management

\section{Over-Supply and Localization Choices}

The highly intense competition businesses have to face in many of today's markets is due to the complex interaction of many factors: over-supply ${ }^{1}$ (the proliferation of brands and products, way beyond demand absorption potential), the importance of time $^{2}$ in manufacturing processes and in satisfying demand, globalisation processes and environment instability (and the ensuing business instability).

Businesses confronted with this complexity find new ways to face the manufacturing problem, and hence its relationship with time and space (manufacturing localization). The existence of markets dominated by the mechanisms typical of over-supply stimulates businesses to search for manufacturing solutions that can combine manufacturing time requirements (the need to reduce the action-reaction times related to demand requirements) with spatial requirements (the importance of controlling the areas deemed important for

* Lecturer in Management, University of Milan-Bicocca (mariaemilia.garbelli@ unimib.it) 
success in certain countries with strategic manufacturing units). Businesses appear to be responding to these requirements through complex mechanisms aimed at developing the competitive relationships either 'individually' or in association with other businesses, such as suppliers, distributors, or even competitors.

Businesses meaning to face the competitive struggle while keeping an 'individual' form often go through a radical re-thinking of their 'role' and their organisation, and through the massive recourse to outsourcing strategies. Hence internal business skills undergo a progressive reduction until only the so-called 'core business' remains under its strict and sole control.

On the contrary, facing competition by associating with other businesses means activating intense mutually advantageous relationships in which two or more companies give up the absolute control they previously enjoyed over certain spheres to 'share' and exploit the synergy they are able to generate by their association. In this situation, competition follows different rules.

$\square$ For example, in the graphics industry '...the role of international
cooperation is increasing... With increasing complexity in products and
services (and the related value added processes), traditional
competition between companies has been replaced by a situation in
which competition takes place between value added chains and
competing networks. Competitive advantage can be obtained through
integrating administrative functions and going beyond the limits of the
individual businesses (customers, producers and suppliers)'.

Manufacturing localization in over-supply markets is thus a particularly complex problem for which the solution is not easily identifiable. The starting point is the set of principles on which a localization choice is usually based (proximity to the outlet and supply markets, state-related incentives, etc.). However, such a choice cannot be made without taking several additional factors into account - from the unsold goods problem (that part of manufactured volume not absorbed by demand) ${ }^{3}$ to the abovementioned cooperation between companies - characterizing the markets in which the company intends to be present.

Manufacturing localization in an over-supply situation is obviously very different from localization characterizing markets in which demand is markedly higher than manufacturing capacity. Indeed, in a scarcity economy, manufacturing is naturally localized near the sources of supply, energy resources and raw materials that are crucial for the company. In craftsman manufacturing, the prevalent business model in an undersupply situation is where the business concentrates its efforts on manufacturing and plant capacity development. It is thus driven towards elementary manufacturing localization choices, namely, dual proximity to supply and markets.

The business considered as a "living system, ${ }^{4}$ relies mainly on its ability to respond to external stimuli to survive and acquire competitive advantage. It is therefore of paramount importance to understand the environment it relates to, the main environment features and the threats and opportunities it conceals.

In this sense, a business operating in a scarcity economy is driven to static localization mainly by the need to be close to energy resources. This static nature is based on the behavioural stability of both demand and competition. Such stability favours localization choices based on a few large manufacturing units and thus determines sizable fixed costs that can only be absorbed in the long term. On the 
other hand, a business competing in over-supply markets must be able to quickly change manufacturing localization choices if there is an advantage in doing so (if particularly favourable conditions appear in different locations - either in the same country or otherwise), thus pursuing dynamic localization policies.

\section{Static Localization}

\subsection{Focus on Manufacturing}

'Static localization' is the manufacturing localization strategy adopted mainly by businesses for which the demand and competition context does not appear to be likely to change in the short term. Producers using craftsman-type processes as a business strategy and/or companies in which the manufacturing function is the most important aspect usually dominate such an environment. Product volumes are constrained by plant manufacturing capacity for the processes involved and the skill level of the workforce employed. In particular, in the case of craftsman processes, manufacturing is characterized by long manufacturing times on the one hand, and a high degree of flexibility on the other. Supply is definitely lower than the volumes and variety requested by demand. The craftsman-businessman is aware of the size of the unsatisfied potential market and concentrates his efforts on the manufacturing function in endeavouring to increase and improve supply. The effort to optimise time and resources stimulates the search for efficient plant and machinery and for the best use of the workforce.

$\square$ The automotive industry probably provides the best-known example of a rapid series of changes involving manufacturing. Innovation brought to the organization of work and resources on the assembly line, as postulated by Taylor ${ }^{5}$, turned out to be essential for the success of Ford (whose competitive advantage was based precisely on Taylor's specialization and uniformity of manufacturing) in the manufacture of the famous 'Model T'. The quantities produced increased and prices fell (resulting from economies of scale).

Competitive advantage based on manufacturing ability emphasizes the efficiency of tools and machinery, the principle of economies in the purchasing and use of raw materials and other resources, and the explicit pursuit of the law of experience for the implementation of processes. With the development of mass manufacturing, large quantities of identical goods become available at moderate cost (and price) and at remarkably shorter lead times compared to craftsman-style manufacturing.

The context in which mass producers operate is characterized by a level of demand that is much higher than the capacity of supply to produce (D>S). This condition is a source of certainty in planning and scheduling: what is offered to potential purchasers will not remain unsold. The business depends on an environment that appears 'stable' to varying degrees. Neither competition nor demand is subject to events that can completely alter the business organisation in the short term for which the business would need to adapt quickly.

Environment stability and the presence of broadly unsatisfied demand induce a business to organize itself around manufacturing needs, as this is the critical business function. When the environment is stable the most 'problematic' function 
for a business is indeed manufacturing; the other functions are developed on the basis of this function. The workforce employed does not possess an in-depth knowledge of machinery operation and of the process as a whole, but performs repetitive, standardized work ${ }^{6}$. Plant and tool maintenance and efficiency levels are entrusted to specialized technicians.

During the first phases of mass manufacturing, demand remains largely unsatisfied $(D>S)$. The market has elementary needs, which businesses satisfy with similarly simple products that are guaranteed to be sold. However, in situations of greater competition induced by increased manufacturing capabilities and an unstable equilibrium between demand and supply $(D \approx S)$, consumer requirements become more precise and specific. Only part of total manufacturing output is sold immediately, the rest remains sellable, 'able' to be absorbed by the market but at a different time. In such a context, commercial activities become more important - in turn complemented by marketing activities aimed at stimulating product purchases from a specific company.

The need to sell is inescapable for businesses. For a mass producer, though, such a principle acquires new meaning: the necessary monetary return (in terms of the profit needed for the business to be financially viable). However, it also requires the business to face a 'problematic' situation in which demand could be won over and satisfied by the competition.

\subsection{Priority: Standardizing to Minimize Cost}

Mass manufacturing overcomes the weaknesses in craftsman-style manufacturing and operates using processes that require markedly shorter production times and produce less raw material waste in order to obtain products at ever lower cost.

In particular, tools and machinery experience innovation dictated by automation, and the whole manufacturing organisation is formed and focused on such tools. At the same time, companies force workers - who in craftsman-style businesses have the 'knowledge', the skills and the ability necessary to make the products (using simple, multi-functional tools) - to adapt to a new role. The role is of unskilled workers using machines to perform a particular phase in the manufacturing process. Therefore, the worker is no longer needed to be able to perform all stages in the manufacturing process and thus make the final product. Workers specialize in the tasks entrusted to them and learn a limited number of tasks. 'Knowledge' stays within the process and the designers behind it.

In mass manufacturing, a company is oriented towards minimizing manufacturing cost, and manufacturing processes are involved in changing the tools used (introduction of automation) and the workforce, whose productivity is explained by the law of experience ${ }^{7}$. Therefore, a business focuses its attention on manufacturing costs as they represent the main factor in determining price but also introduce elements of rigidity in manufacturing ${ }^{8}$. This lack of flexibility is related to the high departmentalisation of processes, in which each individual operation is optimised and specialized (not as a process in itself, but in the context of the whole system) and put under a worker's control. The worker lacks specific technical knowledge about the process or the product but is able to perform specific, limited tasks optimally. Process rigidity is reflected in products characterized by the strong generic connotation of their use ${ }^{9}$. 


\subsection{Long-Term Manufacturing Localization Choices}

Manufacturing localization is a long-term choice for a business in a stable environment ${ }^{10}$. The choice of initial business location is not a critical problem, especially for small or very small businesses. Businesses emerge where the craftsman-businessman lives and manufacturing resources are available. Demand must satisfy his primary needs ${ }^{11}$ and he is willing to move to reach that goal. The business is successful especially if it concentrates on development in the same place (for example requiring sufficient physical space, availability of workforce, etc.).

In situations characterized by primary needs and plentiful demand the prevailing factor in localization is proximity to the source of supply, hence ensuring low transportation costs and an assured supply (Figure 1).

Figure 1: Localization Choices in Low-Demand Markets

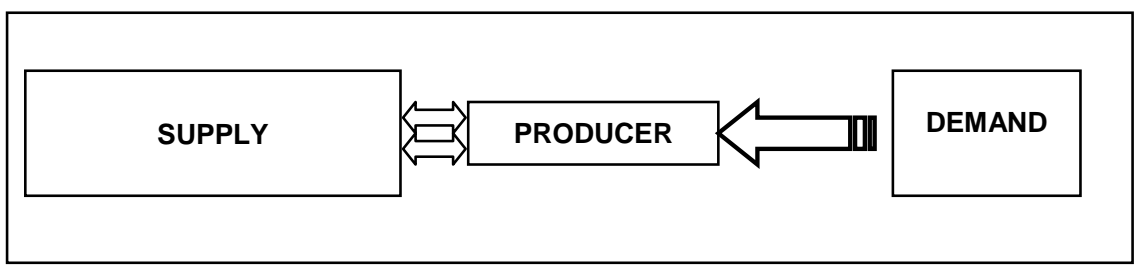

It is not advantageous for the business to operate in more than one location. Geographical splitting would first imply increases in many business costs (especially fixed costs, for example in acquiring or locating sites), and second, the taking on board of non-negligible risks related to multiple locations. It would therefore be an unjustifiable choice as the clear prevalence of demand over supply makes the work carried out at the only location at which the business operates both satisfactory and sufficiently profitable.

A mass producer faces a different market compared to the craftsman-style business: the relationships between supply and demand are tenser and selling is the issue, with commercial and marketing activities taking increasing importance. Demand cannot be suitably satisfied by confining supply to a single site: therefore it could be advantageous for the business to get closer to purchasers by developing local distributors first, and then distributed manufacturing units. The business no longer identifies its competitive advantage only in terms of manufacturing economies of scale and experience, but aims its efforts at obtaining new economies. Economies of logistics are aimed at fixed cost reduction through the use of more specialized techniques and tools for the management of distance and relationships between the business and its co-makers. Other economies are commercial (e.g. the application of marketing knowledge acquired in the original market in new markets), and economies related to purchases (by operating on a larger market - in terms of both territorial coverage and the level of demand to satisfy - the business requires more resources and this allows it to obtain ever lower unit prices from its suppliers) ${ }^{12}$. Government-funded incentives (direct or indirect, such as infrastructure provided to facilitate trading, supply to distributors and bringing supply and demand closer) become the main stimulus to splitting the business into manufacturing units (strategic business units) (Figure 2). 
Static localization is related to a situation of market stability and lasting choices for the business. The word 'choice' itself is associated with an act for which the effects are not limited to the short term, but implies stability over the long term instead. It is important to stress, however, that such stability does not imply invariability or irreversibility in the choices made. A business can change its location choices but only in extraordinary circumstances as the related cost is far from negligible.

Figure 2: Localization Choices in Markets Characterized by Unstable Equilibrium Between Supply and Demand

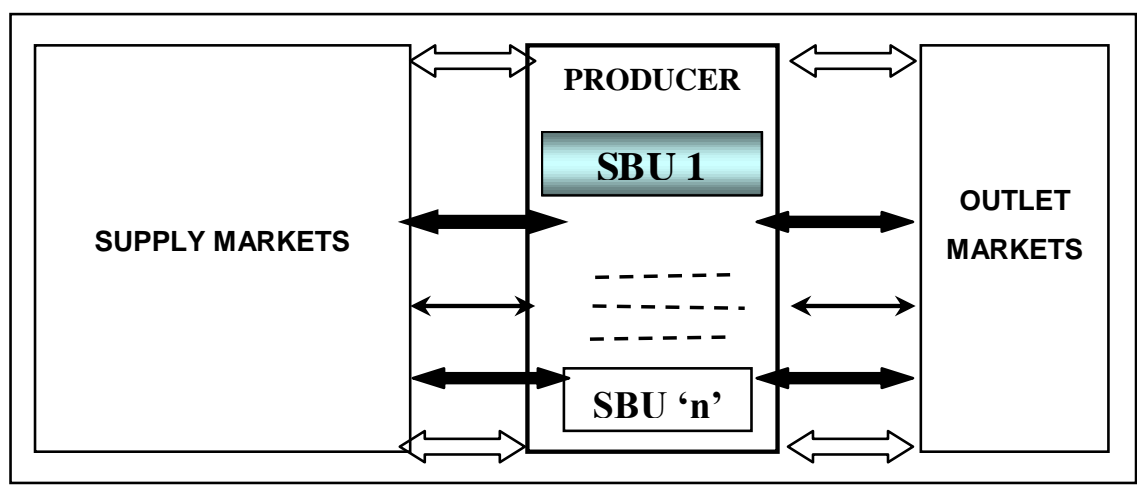

\section{Dynamic Localization}

\subsection{Focus on the Demand Market}

Businesses adopting a dynamic localization strategy face a competitive environment that is fundamentally different from the environment that allows for static localization. The change in the relationship between supply and demand resulting from the development of mass (quantity and variety) manufacturing is of paramount importance.

Supply is far greater than what demand can absorb. Manufacturing capacity increases with decreasing costs due to innovations aimed at process optimisation. Manufacturing is closely tied to the requirement for flexibility inspired by the market in various ways. It evolves incessantly to generate products that meet demand needs in ever better ways at the most beneficial time, in the best way and at the best cost. At the same time, if 'first purchase' demand is relatively limited, the rate of return purchases of products, which have come to the end of their useful lives, or complementary products is important.

Supply presents itself as a set of tangible and intangible values, and the purchaser's choice is determined more and more often by the presence of accessory services ${ }^{13}$. At the same time, the system of company intangibles ${ }^{14}$, such as brand equity, information systems and the culture pervading the organization increases in importance.

Within a highly competitive context, communication becomes a business function of crucial importance in winning customers from the competition. Businesses research and categorise their customers into segments and concentrate their communication activities on such segments to obtain their loyalty or just to persuade them to buy. Plenty of resources are invested in spreading - and 
somehow popularising - the profile that characterizes the business identity and permeates purchases of the product. Thus a product or service choice is not only aimed at those using it, but also at communicating personal attitudes that the purchaser wants to manifest to others.

Consider for example three watch brands, Cartier, Calvin Klein and Swatch. A Cartier customer is conscious of the self-image that his choice will convey: the image of a person with class, living in refined and discreet elegance. Calvin Klein started as a clothing brand that confers the status of a modern, self-confident person on its customers people who are mindful of fashion without betraying it. Watches with the same brand are targeted at customers wanting to assert a strong, stable personality - people able to impose their own style. Finally Swatch, one of the icon brands of the new era, represents every person's freedom to identify with himself: you do not need to find a style outside of yourself, you can freely choose the watch to wear according to your mood - colourful for sports and leisure time, serious and softer coloured when professionalism needs to be emphasized.

In over-supply situations, the time factor comes out as important in competition. Time-based competition ${ }^{15}$, i.e. the kind of competition that identifies the crucial factor to achieve supremacy over competitors as the management of time, implies rapidity in understanding final customer needs and responding to them with a suitable offering. In this context, one can observe significant compression in manufacturing times (time compression), the time needed to reach the market (time to market) and the choice of timing for action (time value) - representing the basics of demand bubbles ${ }^{16}$.

\subsection{Priority: Standardization and Variety}

Businesses invest appreciable resources in setting up the plant and equipment needed to face market requirements. The goal of achieving large-scale manufacturing derives from the need to obtain significant economies of scale and amortize large-scale investments rapidly. However, this introduces substantial structural rigidity by reducing flexibility in the use of resources in the business activity characterizing the business. Geographic location, size and level of flexibility are important competitive factors that must oppose the natural build-up of the causes behind operational rigidity.

In contexts characterized by instability, market-driven ${ }^{17}$ businesses pursue a double advantage: they assign a central role to market requirements while showing open mindedness and a readiness to react to the many rapid changes in the context.

Businesses need manufacturing solutions targeted at associating the advantages of 'standardized' manufacturing with advantages that derive from flexible manufacturing - thus combining internal needs concerning manufacturing, research and development with external needs gathered by the business functions concerned with market analysis. Manufacturing (aiming at gradually achieving cost economies) thus combines with marketing and communication to offer variety at a lower cost. Indeed, the concept of manufacturing technique ${ }^{18}$ flexibility is reflected in the concept of 'variety' in the range of products offered to satisfy demand requirements that change over time and no loyalty in the purchases made. 
With instability in the manufacturing environment, the technological tools used by businesses go though deep, extensive development. Automation introduces new flexibility elements deemed necessary for development of manufacturing processes. The information sphere undergoes a significant transformation, made necessary by the growing importance of 'knowledge'. New tools enter the business: for example the application of data communications technology that facilitates the gathering of information and the more thorough and complete processing of data.

\subsection{Short-Term Manufacturing Localization}

Market instability is reflected in the manufacturing sites, by quickly cancelling out benefits derived from the adopted localization solutions, and thus making it difficult for businesses to make choices, that is, adopting options that remain valid and almost unchanged over the long term. The opportunities and threats emerging from instability in the global system force businesses to develop strategies appropriate to facing the 'competitive dynamism' resulting from the presence of multi-business supply sources and the businesses operating within new spatial and temporal competitive relationships ${ }^{19}$. The presence of multi-business sources of supply leads to remarkably extensive competition processes, and to a high 'death rate' among competitors (the weaker ones, whose offerings are marginal with respect to the market, are thrown out).

The space-time relationships between companies also change: one-dimensional spatial competition appears to lose relevance. A variety of competitive forces in the same geographic area can be found: local, national and international businesses. Increasing competition shortens decision-making times for businesses, which must face fast-changing situations, and highlights the importance of time as a factor in competition (time-based competition).

The dynamic nature of competition is also emphasized by new consumption models, and especially by 'the tremendous physical mobility of people, the widespread popular use of mass media and the learning obtained through net 'surfing', which taken together lead to a widespread knowledge of behaviours and habits and the progressive standardization of the mechanisms by which preferences are formed... In concrete terms, new behaviours emerge based on consumption trends unconstrained by geographical influences that thus facilitate the progressive standardization of supply ${ }^{20}$.

Such remarks apply specifically to business manufacturing localization choices. The relevant decisions are made with the awareness that an unstable market does not allow for the implementation of plans conceived for the long-term. Many business decisions are bound to be modified after a short time. This stresses the need to pursue a 'new business organization' aimed at lightening the organisation while equipping it with flexibility and thus increasing its ability to adapt dynamically to external stimuli. Such reorganization tends to emphasize manufacturing elasticity, strong expansion in research and development and selective perception of context variations. Businesses that reorganize their functions based on such arguments are better able to grasp, and hence exploit financially, the various opportunities offered by the market, including localization.

Economic logic - directing the decentralized development of businesses in international markets - induces businesses to move dynamically in a worldwide context to quickly seize on the advantages offered by different locations. The 
temporary advantage that makes a certain location more appealing than another induces businesses to create contacts with financial institutions already operating in the places where they intend to operate, or to make direct investments.

For businesses operating in an over-supply situation, the concept of localization choice is no longer right due to the temporary nature often characterizing the 'advantage' associated to a certain place and the consequent propensity by businesses to change the choices made. The expression advantage evaluation evokes ways of moving that are necessarily dynamic. Instead, the concept of choice suggests a static propensity to maintain unchanged the choice made by the business.

The choice of a given location assumes stability of the system as a given: the commitment needed to adopt the choice requires a long time to amortize the costs. In this sense, localization becomes a constraint to the development of a business. Should the context and the forces operating in it undergo a sudden transformation, it would be difficult for a business to adapt to the new conditions as a localization choice is supported by heavy investments (for example the purchase of the site where the manufacturing plants are built and the purchase of the machinery used in processes).

Conversely, in markets characterized by instability, businesses tend to lighten their organisation and free them up as much as possible from the constraints that strongly limit the potential for action. Therefore, manufacturing flexibility is not the only solution able to provide businesses with the ability to adapt, but is complemented by the dynamic nature of how localization is handled.

\subsection{System of Relationships and Manufacturing Sites}

Businesses in an over-supply situation thus face particularly intense competitive situations. This fact means giving priority to business solutions that let companies face environment complexity and variability optimally. Such solutions involve the business as a whole, and in particular the size of the business, localization choices, and the system of relationships with the outside world.

By modifying its organisation, a business aims at increasing its competitiveness in a market - dominated by over-supply - where highly intense competition forces it to undergo restructuring aimed at progressively decreasing fixed costs, introducing information and communication technology (ICT) and adopting flexible plant.

A policy of fixed cost reduction - radically modifying the structure of business costs - frees a business from the static character imposed, for example, by amortization periods and the financial burden.

Examples are the choice to rent rather than buy the area in which to place the plants, or the choice to lease the equipment and machinery employed instead of acquiring them. The reduction in fixed costs is also implemented by the search often performed worldwide - of the regions or countries in which specific cost categories appear more advantageous.

$\square$ In the computer, electronics and telecommunication sectors many companies are '... hunting for places where labour is cheap to delocalise manufacturing plants... Take Hungary: after seven years of a profound presence in the country, this year IBM cut 3,700 jobs at its hard disk manufacturing plant in Székesfehérvàr with the goal of moving all manufacturing to China. Philips is about to do the same, 
according to persistent rumours in the local press ${ }^{21}$. This happens in a country such as Hungary, where multinational corporations own $90 \%$ of the manufacturing sites. Evidently such dynamism in localization is also made possible by the adoption of lightweight organisation choices that allow for the compression of fixed costs.

The adoption of particularly flexible plants is a sign of the need to exploit resources characterized by a high potential for alternative use.

\begin{abstract}
$\square$ Among the most significant cases, Pirelli's MIRS system (Modular Integrated Robotized System) stands out. It is a '... modular manufacturing system, extremely flexible and completely robotized. The high degree of automation makes MIRS advantageous in countries like the United States, where the cost of labour is high, since human presence is limited to specialized technicians with supervisory tasks. The ten small robots used in the manufacturing process ... can produce a sequence of tyres of any type and size by simply changing the software program.' This allows the company to produce lots that are made up of even a single tyre.
\end{abstract}

The adoption of choices that break up a large business concentrated at a single location to create small plants, based on complex localization factors - such as proximity to supply and outlet markets, availability of government incentives, fast disinvestments potential in a given area - implicitly expresses the need to reduce action-reaction times (time compression).

Over-supply requires a business to satisfy the changing requirements of an unstable market in a very short time (time to market). A small plant with flexible machinery is at an advantage, as it is more easily adapted to change compared to a large mass-manufacturing unit with rigid plants. Evidently the potential to exploit such structures and then proceed to rapid disinvestment (small plant size allows for a wide margin of action) deeply influences localization choices, by characterizing them with a dynamism that is inconceivable for a mass producer.

The business reorganization required by over-supply often induces businesses to boost the system of relationships with the outside world through outsourcing and sharing business processes - typical of market-space competition - with other businesses upstream or downstream in the manufacturing chain (vertical cooperation) or with competitors (horizontal cooperation).

In the former case (vertical cooperation) a business follows a policy dominated by outsourcing, thus giving up direct control over some business processes (especially collateral activities, necessary but not pertaining to the core business). This option is often chosen by businesses intending to make some phases of the manufacturing process more flexible, but the necessary skills are not provided in-house. Outsourcing is also chosen to exploit the professional skills of special suppliers whose businesses concentrate on processes outsourced by other companies (hence taking advantage of the experience accumulated by such businesses).

$\square$ Pirelli, a sub-supplier to many large automotive companies, has designed and is implementing an innovative process (called MIRS Modular Integrated Robotized System) for the manufacture of tyres with the goal of reducing the cost to customers. It is an innovative system in 
that it allows, among other things, to '...move manufacturing directly to the car producers' plants ... The revolution in this sector, that has always featured huge industrial plant, is epochal in character', as it envisages '... one of the most modern concepts of plants, conceived as a model integrated into the plant architecture or the assembly system ... thus very significantly reducing the average material transit time from the raw material storage location to the finished product location'. These plants can also be '... strategically located in the country according to the needs of the core market ${ }^{22}$.

Horizontal cooperation is instead carried out through a system of relationships with competitors, including direct ones. In this case the business intends to pursue the minimization of so-called competition costs ${ }^{23}$, i.e. those business costs for which sharing is an important optimisation tool and hence, for achieving a position of advantage compared to sole competitors. These costs include research and development for outsourced and shared projects, manufacturing costs (for parts or components not involved in product differentiation) and marketing costs when handled through joint means. Alliances and joint ventures are the most common forms of cooperation used to achieve a specific competitive edge. They arise to contain some costs, but at the same time allow for ownership to remain unchanged and the relationship to be dissolved should the related advantage disappear.

$\square$ An example is the cooperation between Fiat Auto and Suzuki for the manufacturing of SUVs (sport utility vehicles). The agreement provides that '... starting in the autumn of 2005 the Magyar Suzuki plant in Estergom, in the northern outskirts of Budapest, will produce 60,000 SUVs (20,000 for Fiat and 40,000 for Suzuki) every year... the Turin company will be able to take advantage of Suzuki's solid experience in this market segment' (the so-called 'off-road city vehicles').

PSA expressed its intent to expand its business in Eastern Europe with a manufacturing plant in Slovakia. The site under preparation will be added to the nine existing sites in Europe and the manufacturing centres. The latter are centres 'built together with other producers within joint ventures for engines (with BMW and Ford), gearboxes (Renault), minivans and commercial vehicles (with Fiat)'. PSA intends to gain sizable advantages in terms of cost from these sites ${ }^{24}$.

By manufacturing site we mean a manufacturing plant where competition costs are minimized through the implementation of horizontal agreements between businesses. The running of such sites appears indeed to be related to the search for, and the dynamic management of, relationships with direct competitors.

Clearly the existence of such an organisation is intimately connected to the choices of business reorganization (for the reduction of fixed costs) aimed at giving flexibility to the business. It is, indeed, clear that the solutions mentioned above imply a reduction in business size and hence a better ability to adapt to the context. At the same time, solutions such as an agreement between two producers to manufacture a common component at a single plant, the signing of an agreement for specific project research and development to be outsourced by the businesses involved to external 
research organisations, manufacturing product components under contract on behalf of a competitor are all solutions characterized by a strong component of flexibility.

The ability to change quickly at ever-lower cost can be carried out at the strategic level first, and then translated into site operations. This suggests that business localization can acquire a dynamic character, and that such dynamism can be made concrete in two main ways.

First, there can be a 'physical movement' of plants to different places (as in the case of geographically centralized businesses dividing themselves into smaller strategic business units (SBU), or in the case of the transfer of an SBU to a different location).

Second, dynamism can be implemented by agreements between businesses. A cooperative manufacturing agreement at a competitor's plant (the Fiat-Suzuki case) allows for a presence (albeit not independently) in an area. At the same time, the agreement implies loss of control over the site - thus manifesting the dynamic nature of manufacturing localization without any physical movement (of machinery or other tangible assets).

\section{Bibliography}

Brondoni Silvio M., Brand Policy and Brand Equity, Symphonya. Emerging Issues in Management (symphonya.unimib.it), n. 1, 2000-2001. http://dx.doi.org/10.4468/2001.1.02brondoni

Brondoni S.M., Comunicazione, risorse invisibili e strategia competitiva d'impresa, in S.M. Brondoni (ed.), La comunicazione d'impresa, Sinergie, CUEIM, Verona, n. 43-44, MayDecember 1997.

Brondoni S.M., Politiche di mercato dei beni industriali, Giuffré, Milan, 1983.

Cappelletti M., Alleanze strategiche: la cooperazione interaziendale come alternativa alla fusione, Graphicus, April 2003.

Corniani M., Sistema informativo aziendale e dinamiche competitive, Giappichelli, Turin, 2000.

Di Gregorio A., La valutazione della strategia, Utet, Turin, 1996.

Gallinaro S., La produzione nell'economia dell'impresa industriale: da 'funzione' a 'scuola', Giappichelli Editore, Turin, 1996.

Gnecchi F., Ricotti P., Brand Portfolio Reengineering. The Gruppo Coin Case, Symphonya. Emerging Issues in Management (symphonya.unimib.it), n. 1, 2000-2001. http://dx.doi.org/10.4468/2001.1.05gnecchi.ricotti

Golinelli G.M., Gatti M., The Firm as a Viable System, Symphonya. Emerging Issues in Management (symphonya.unimib.it), n. 2, 2000-2001.

http://dx.doi.org/10.4468/2001.2.04golinelli.gatti

Golinelli G.M., L'approccio sistemico al governo dell'impresa, volumes I and II, CEDAM, Padua, 2000.

Kotler P., Scott W.G., Marketing Management, ISEDI, Turin, 1993.

Lambin J.J., Chumpitaz R., Market-Orientation and Corporate Performance, Symphonya. Emerging Issues in Management (symphonya.unimib.it), n. 2, 2000-2001. http://dx.doi.org/10.4468/2001.2.03lambin.chumpitaz

Lambin J.J., Market-driven management. Strategic and Operational Marketing, MacMillan Press, London, 2000.

Lugli G., Efficienza del commercio e stabilità dell'industria, Franco Angeli, Milan, 1985. 
Maggioni V., Il sistema informativo aziendale, CEDAM, Padua, 1983.

Monden Y., Japanese Cost Management, Imperial College Press, London, 2000.

Piore M.J., Sabel C.F., Le due vie dello sviluppo industriale. Produzione di massa e produzione flessibile, ISEDI, Turin, 1987.

Porter M.E., Il vantaggio competitivo, Edizioni di Comunità, Milan, 1995.

Rossano L., Gestione e controllo dei processi produttivi, Franco Angeli, Milan, 1999.

Scicutella M., La gestione d'impresa, Cacucci Editore, Bari, 1999.

Taylor F.W., Principles of Scientific Management, Harper \& Row, New York, 1911.

Toffler A., L'azienda flessibile, Sperling \& Kupfer Editori Spa, 1990.

Vitale L., La minifabbrica si sposta dai clienti, Il Sole 24 Ore, 18 December 2000.

\section{Notes}

${ }^{1}$ For an ampler discussion on the subject see S.M. Brondoni, Comunicazione, risorse invisibili e strategia competitiva d'impresa, in S.M. Brondoni (ed.), La comunicazione d'impresa, in Sinergie, CUEIM, Verona, no. 43-44, May-December 1997.

${ }^{2}$ We refer to the concepts of time compression and time value, characterizing over-supply markets. See S.M. Brondoni, A. Giulivi, Competizione 'time-based' e nuova progettualità della comunicazione aziendale, in Sinergie, Quaderno n. 9, November 1993.

${ }^{3}$ Businesses are indeed marketing offerings that are ever more varied and tailored to the needs and desires of customers, thus demonstrating openness to the external world and a readiness to quickly grasp the stimuli from their markets. By optimising the processes to provide a qualitative and quantitative manufacturing level that is higher than demand absorption potential, businesses are faced by intensified competition and the problem of unsellable goods - that is products that cannot be placed.

${ }^{4}$ See. G.M.Golinelli, M. Gatti, L’impresa sistema vitale. Il governo dei rapporti sistemici, in Symphonya. Emerging Issues in Management, Istituto di Economia d'Impresa, University of MilanBicocca campus, Issue 2, 2000-2001.

${ }^{5}$ F.W. Taylor, Principles of scientific management, Harper \& Row, 1911.

${ }^{6}$ See the following sections for considerations concerning the law of experience and economies of learning.

${ }^{7}$ According to the law of experience, the unit cost corresponding to the value added by the same product decreases by a fixed and predictable percentage each time the cumulative total manufacturing doubles. The following distinct causes of the effect of experience can be identified:

-efficiency of manual labour, obtained through the continual repetition of the same operation by a worker;

- specialization in work and methods;

- new manufacturing processes resulting from the adoption of more and more sophisticated tools;

- better manufacturing equipment;

- change in the resources used (use of less expensive resources);

- new product conception.

See W. Abernathy, K. Wayne, The limits of the experience curve, Harvard Business Review, September-October 1974, pp. 109-119.

8 'Thus, the introduction of automated equipment increased manufacturing rigidity, making it even more difficult to use the resources for alternative purposes', see M.J. Piore, C.F. Sabel, Le due vie dello sviluppo industriale. Produzione di massa e produzione flessibile, ISEDI, Turin, 1987, p.51.

9 'Mass manufacturing (...) denotes the manufacturing of generic products through the use of specialized resources. The more generic the products, and the wider the variety of their uses, the wider their market; but also the machinery must be more specialized and the work needed to manufacture them must be more fractioned'. M.J. Piore, C.F. Sabel, Le due vie dello sviluppo industriale. Produzione di massa e produzione flessibile, op. cit. 
${ }^{10}$ Stability characterizes the environment context of both craftsman-style and mass manufacturing businesses. In the short term, the market does not undergo sudden evolution due to deep changes, involving the structure of the environment and financial institutions apt to cause instability in the business. The environment evolves without shocks. In the long term, changes take place that are significant, but in some measure expected, to which the business can react by a coordinated and ongoing process of adjustment over time. The market boundaries are clear, innovations in the business infrequent and the relationships with other market agents are strong, having being built over the years and destined to last a long time. Such a situation induces businesses to make financially advantageous choices carefully but safely: a decision made with prudence is valid in the long term precisely because of the static nature of the system.

${ }^{11}$ A.H. Maslow, Motivation and personality, Harper \& Row, New York, 1970.

${ }^{12}$ It is possible, however, to identify other factors inducing businesses to decentralize their activities. 'The decentralization phenomenon can also be attributed to the intent to overcome institutional constraints (union power, absenteeism, etc.), to decrease workforce employment rigidity and boost productivity', M.E. Porter, La strategia competitiva, op. cit., p. 255 ff.

${ }^{13}$ For example support, warranty and replacement services.

${ }^{14}$ See S.M. Brondoni, Comunicazione, risorse invisibili e strategia competitive d'impresa, op. cit.

${ }^{15}$ See G. Stalk Jr., T.M. Hout, Competing against time, The Free Press, New York.

16 See M. Corniani, Sistema informativo aziendale e dinamiche competitive, Giappichelli, Turin, 2000 .

17 'The market orientation concept, de-emphasizes the functional roles of marketing departments, enlarges the market definition to key market players (and not only to the customer) and states that developing customer relations and enhancing customer value is the responsibility of everyone in the organisation.' see J.J. Lambin, Market-Driven Management, Macmillan Press Ltd, op. cit. Grasping changes in the environment is a vital need for businesses: the optimisation of the manufacturing processes, through the use of more productive resources and the minimization of waste, is important, but not sufficient. The market-driven management approach and the system of intangible assets (brand equity, corporate culture and information system) increase in importance. While primarily striving to satisfy customer needs, a business studies all the market players in depth (customers - purchasers or users - current and potential competitors and their products, suppliers and co-makers) able to influence the business in different ways. The market orientation emphasizes the manufacturing aspect, but directs it towards satisfying the needs and opportunities offered by the market, and involves the whole organization in this competitive process.

18 To obtain high manufacturing flexibility, businesses use machinery able to produce standardized and different goods at the same time. To this end, the high cost and rigidity of plant organisation and centralized material flow control have been gradually reduced by the introduction of computers. This has been not only for operating digital control machinery, flexible manufacturing systems (FMS) and assembly systems and industrial robots, but also in design (Computer Aided Design - CAD), process planning (Computer Aided Process Planning - CAPP), engineering (Computer Aided Engineering - CAE), and manufacturing (Computer Aided Manufacturing CAM)', see M. Scicutella, La gestione d'impresa, Cacucci Editore, Bari, 1999, p. 109 ff.

19 'Traditional competition methods, based on the expansion in sales of a limited number of products ... recently underwent a radical modification. Business development policies of merely quantitative nature have been abandoned in general and replaced by more evolved strategies... In this sense special relevance must be attributed to businesses operating through a complex aggressive strategy and 'multi-brand' and 'multi-market' competitive behaviours. Their firm orientation towards competitive 'customer satisfaction' prevents fossilization in fixed product types, and, at the same time, stimulates an obsessive search for innovative matches between supply gaps and unsatisfied customer needs', see S.M. Brondoni, Comunicazione, risorse invisibili e strategia competitiva d'impresa, op. cit., pp. 4 and 5.

${ }^{20}$ S.M. Brondoni, Comunicazione, risorse invisibili e strategia competitiva d'impresa, cit., p. 6.

${ }^{21}$ Ungheria a rischio delocalizzazione, Il Sole 24 Ore, 29 November 2002. 
${ }^{22}$ L. Vitale, La minifabbrica si sposta dai clienti, Il Sole 24 Ore, 18 December 2000.

23 'The construction of a relationship between companies profits them both by leading to immediate cost reduction and innovation in order to fight successfully against competition, and in the development of new products.', Y. Monden, Japanese Cost Management, Imperial College Press, London, 2000.

${ }^{24}$ Such logic can be ascribed to the logic of non-duplication of costs. This is the case of costs sustained in the same sphere by two or more competing businesses. By agreeing to share the expenses, a remarkably increased advantage in the results obtained with the same financial burden ensues. 